\title{
From House Construction to Life Building-Real Estate Advertisements Planning through Emotional Appeals and Cultural Feelings
}

\author{
Mo-ran WANG ${ }^{1}$, Xiu-juan GUO $^{2}$ \\ ${ }^{1}$ Inner Mongolia Technical College of Construction, Hohhot, China \\ ${ }^{2}$ College of Fine Arts, Inner Mongolian Normal University, Hohhot, China
}

Keywords: Cultural Feeling; Emotional Appeals; Real Estate Advertisement.

\begin{abstract}
The 19th National Congress of the Communist Party of China has pointed out that houses are used to live, not to speculate. Consumers should be guided by national policies to purchase houses rationally, and houses should return to its fundamental property of living. Nowadays, consumers no longer seek the simple living function of houses. Therefore, house developers and house agents should not guide consumers from the perspectives of investment or properties in their real estate advertisements. By contrast, their full attention on consumers' cultural feelings can deeply arouse their purchasing desire. As an important way of cultural feelings, emotional appeals move consumers' emotion, and promote them to purchase.
\end{abstract}

\section{Introduction}

The term emotional appeal means resorting to people's emotion in the process of appealing and focusing on the harmonious relation between product and man. It can trigger people's emotion on a product and further call their need and identity on the product. In this way, interest of the spirit level can start consumers' association, triggering their emotional resonance. Basically speaking, emotional appeal is to respect man and human nature, affirming the dominant role of man when using a product. In the design of real estate advertisement, emotional appeal is that the feature of the house should be introduced to the consumers from their perspectives. The introduction on the happiness of living in such houses can trigger their association of living in them.

Nowadays, the manifestation forms and designs become more and more diversified, and the emotion between people becomes indifferent. Designers should attach importance to the effect of emotional appeal in real estate advertisement, attracting consumers' recognition by emotionally changing their inventions from building houses to building life, which can not only increase consumers' perceptual knowledge and recognition on the houses, but also trigger their desire to buy. Therefore, it is of high importance to make a study on the real estate advertisement designers' human cultural feelings.

\section{Features of Human Cultural Feelings in Real Estate Advertisement}

Human culture refers to different cultural phenomena of human society. [3] It is the advanced and core human culture, that is, advanced values and value norms. Chinese human culture is both a "culture" with "human" as its foundation and "human" with "culture" as the essence. It produces ritual and music culture, ethical culture and survival culture through the regulation of the relations between human and culture, society and spirit. Humanistic spirit means an interpretation of human life and dignity, significance and value, which is both a metaphysical pursuit and a physical consideration. Modern Chinese Dictionary defines humanistic spirit as the thought and action which propose people as the foundation, emphasize people's value, respect people's dignity and rights, care for people's realistic life and pursuit human's freedom, equality and liberation. In design history, human cultural feelings can be traced back to 1851 when Great Exhibition was held in London. William Morris, a seventeen-year-old boy went to visit the exhibition with his mother. As soon as they entered a crystal palace exhibition hall, Morris cried "What a horrible monster!", refusing to visit those poorly shaped products. This experience made Morris devote himself to his design career. The art and craft movement initiated by William Morris also initiated modern design, 
with which as the landmark, some artists began focus on the relationship between people and machine, asserting any products invented by human being, including machines and furniture, should serve people. A typical example is the deep study of human engineering.

People's consumption demands can be divided into three levels. The first level is the surviving level which deals with the basic demands of life including food, clothing, housing and travelling. The second one is security demand and social demand, which satisfy the demands with common features. The third one is the requirement of self-fulfilling, which pursues personality and difference. Based on a universal meaning, the first two demands take material satisfaction as the foremost premises. The third one, based on particularity, satisfies different requirements of consumers, pursuing spirit satisfaction.

Human cultural feeling in advertisement refers to the concern of human and human nature, as well as the satisfaction of people's feeling when living in the houses. It emotionally satisfies the consumer's demands and pays close attention to their long-tern interests. A good quality house can make the consumer self-value come true, and a unique house can meet their psychology of pursuing individuality and difference. Through the shaping of human cultural feelings, the consumers could arouse interests on the houses, thus stimulating purchases.

The Juliets have lived in a house in Grenoble City, France for three years and now they decide to sell it. Mr. Juliet has been travelled and lectured around the country these years, and every three or two years they would move, sell house and purchase house again. This time they make five-day house-selling advertisements on newspaper as usually. The first advertisement says: if you want to by house, please pay close attention to this information at least for five days. I suppose you would like to spend a longer time to choose a favorite house which could bring you a simple but happy life. Our daily life in this house happens in this way: At five o'clock every morning, the beautiful bell tone from the church would come into our ears, in which we become used to get up leisurely. The bathroom is the best place to enjoy the landscape where you can stand before the window and enjoy the green grassland nearby and mountains faraway while washing face and brushing teeth. Under the window is the bathtub where, in winter, you can soak in warm water and overlook the distant beautiful mountains covered with snow. Welcome to our second house-selling information: While I am writing these words under the corridor behind the kitchen, my husband is planting sweet irises in the garden. Every may when sweet irises are in full blossom, you can sit under the corridor, like me, watching the beautiful flowers and flying butterflies. You will feel you life is as beautiful as these flowers. [2]

These advertisements don't mention simple numbers on the area or rigid description of the house layout, but each aspect which shows the couple's love to the house. Each time Mrs. Juliet wrote these advertisements, she was always sentimentally attached to the house, showing the enjoyments the house has brought to her husband and her. What she writes is not the house itself, but the beautiful feelings of living in it.

\section{The Expression of Human Cultural Feelings in Real Estate Advertisements}

\section{The Influence of the Increasing of Middle Class on the Expression of Human Cultural Feelings}

In recent years, with the improvement of social life, the number of middle class is increasing rapidly, who play an important role in social life. However, middle class is not the people whose income is between sixty to five hundred thousand dollars a year, and can't be defined according to their job nature or occupations. As American Zero Point Investigation Corporation shows, 26\% of Chinese living in big and medium-sized cities thinks they are living a life better than average, namely middle class.

Middle class is a representative of the social classes, the dream of a country, as well as an important mark of coming out of the "dumbbell" society and entering "olive" society. It plays an essential part to the orderly development of a society, to the cooperation and distribution of a society, to the fulfillment of social tasks and to the satisfaction of social needs. Middle class rises 
and grows into an enormous social class, separating the impact from the upper social class and lower social class and becoming the mainstay of a society.

Mature middle class should be defined according to their working status, educational level, cultural cultivation and every their job category. They should have stable income, regular living habits and cultural deposits. They go travelling in holidays sometimes, liking following the fashion and caring for social current affairs. What's more important is that they should have their own separate space and houses owned by them.

In this sense, real estate developers should pay attention to these features. The spiritual need of middle class is much more than the material need, while the latter is the dependent of the former. If these aspects have been concerned, it is obvious to see the relationship of building houses and building life. Hence construction area, house layout, location and inappropriate foreign construction style can not simply attract this high grade population. If the advertisement is designed from the house buyer's psychology and their daily life, their attention can be attracted, their desire to buy thus arousing.

\section{The Maturity of Real Estate Market Requiring Real Estate Developers to Focus on the Expression of Human Cultural Feelings}

Nowadays, real estate advertisements are of varying quality. An important bottleneck blocking real estate development is lack of project theme, construction style and marketing arrangement. It is in fact irresponsible that some projects assert that they focus on the product, refusing concept publicity. Providing products of good quality is a necessity and the lowest requirement for the developer, which, however, should not become an excuse not to make progress. Idea is the soul of a good real estate, theme being the key issue, style being the skeleton. Only fully attention on the above features can produce high-quality products.

Moreover, some concepts are being abused. With the progress of the reform and opening-up policy in China, Chinese have continually accepted new thoughts and ideas. But some enterprises abuse some concepts, stealing some concepts superficially. Some even make up isms, themes and concepts to misunderstand English or simply piece English together, which brings consumers into a wrong way. These conceptual influences are even bigger than material harms, more importantly being a cultural kidnap. Product value can not be increased by the means such as visual effect pursuing in the selection of pictures, use of surface metaphors and association in advertising messages, abuse of foreigners and other persons to make sales promotion, and subservience with Hongkong and Taiwan accents. Just like the Indian waiter standing in front of the hotel entrance at Shanghai Beach in the $20^{\text {th }}$ century, a high-grade community, if advertised by such kind of advertisements, however, will be put a label of inappropriate foreign copies or fakes, and the quality of the houses themselves is difficult to accomplish.

\section{Conclusion}

Houses are not an ordinary consumption for most of the families. A house, which carries the expectation of the families for a happy life, can be bought after many years of saving of the families. Therefore, developers should not only guarantee the quality of the houses they build, but also pay full attention to the living environment. Only in this way can consumers fully feel what their buy is not simply a house, but a life style, a life attitude and a happy and warm home.

\section{References}

[1] Chao Jizhou \& Han Jingti. Modern Chinese Dictionary the fifth edition [M]. The Commercial Press, 2005

[2] Cui Shuyu. A Frenchman's House-selling Advertisement [J]. Readers, 2011 (22): 38-39

[3] Shu Xincheng. Modern Words Origins of A Collection of Words [M]. Shanghai Dictionary Press, 2010. 
[4] Wang Shouzhi. World Modern Design History [M]. Chinese Youth Publishing House, 2002.

[5] Zhao Xiaoyan. Emotional Factors in Commercial Advertisement Persuasiveness [J]. Ornaments, 2015 (1): 56. 